HAZENCLEVER LOPES CANÇADO JÚNIOR

\title{
MOVIMENTOS SOCIAIS E COAUTORIA CONSTITUCIONAL
}

Dissertação de Mestrado

Orientador: Prof. Dr. Conrado Hübner Mendes

UNIVERSIDADE DE SÃO PAULO

FACULDADE DE DIREITO

SÃO PAULO - SP

2018 


\section{MOVIMENTOS SOCIAIS E COAUTORIA CONSTITUCIONAL}

Dissertação apresentada à Banca Examinadora do Programa de Pós-Graduação em Direito, da Faculdade de Direito da Universidade de São Paulo, como exigência parcial para a obtenção do título de Mestre em Direito, na área de concentração Direito do Estado, sob a orientação do Prof. Dr. Conrado Hübner Mendes.

UNIVERSIDADE DE SÃO PAULO

FACULDADE DE DIREITO

SÃO PAULO - SP 
TERMO DE APROVAÇÃO

HAZENCLEVER LOPES CANÇADO JÚNIOR

\section{MOVIMENTOS SOCIAIS E COAUTORIA CONSTITUCIONAL}

Dissertação apresentada à Banca Examinadora do Programa de Pós-Graduação em Direito, da Faculdade de Direito da Universidade de São Paulo, como exigência parcial para a obtenção do título de Mestre em Direito, na área de concentração Direito do Estado, sob a orientação do Prof. Dr. Conrado Hübner Mendes.

Orientador:

Prof. Dr. Conrado Hübner Mendes

Prof. Dr. Virgílio Afonso da Silva

Prof. Dr. Diego Werneck Arguelhes

Prof. Dr. Daniel Sarmento

UNIVERSIDADE DE SÃO PAULO

FACULDADE DE DIREITO

SÃO PAULO - SP

2018 
Autorizo a reprodução e divulgação total ou parcial deste trabalho, por qualquer meio convencional ou eletrônico, para fins de estudo e pesquisa, desde que citada a fonte.

\title{
Serviço de Biblioteca e Documentação
}

Faculdade de Direito da Universidade de São Paulo

\author{
Cançado Júnior, Hazenclever Lopes \\ Movimentos sociais e coautoria constitucional / Hazenclever Lopes \\ Cançado Júnior. - São Paulo: USP / Faculdade de Direito, 2018. \\ $149 \mathrm{f}$.
}

Orientador: Prof. Dr. Conrado Hübner Mendes

Dissertação (Mestrado), Universidade de São Paulo, USP, Programa de Pós-Graduação em Direito, Direito do Estado, 2014.

1. Movimentos sociais. 2. Cultura constitucional. 3. I. Conrado Hübner Mendes. II. Título. 
"Hay hombres que luchan un día y son buenos. Hay otros que luchan un año y son mejores. Hay quienes luchan muchos años, y son muy buenos. Pero los hay que luchan toda la vida: esos son los imprescindibles."

(Bertold Brecht, recitado por Milton "Bituca" Nascimento, em $8 / 12 / 2018)$

"Não sou capaz de apontar rumos, e não gosto que em geral eles me sejam apontados. Somos tão pequeninos diante da realidade...

Mas as mudanças se operam, e é preciso ter confiança no espírito criativo dos homens."

(Carlos Drummond de Andrade, em resposta escrita em 21/11/1976, quando questionado sobre os rumos da literatura por um estudante de ensino médio no Rio de Janeiro que viria a se tornar meu professor universitário) 


\section{RESUMO}

Cançado Júnior, Hazenclever. Movimentos sociais e coautoria constitucional. 149 folhas, Mestrado - Faculdade de Direito, Universidade de São Paulo, 2018.

Cortes constitucionais estabeleceram-se como incontestáveis arenas de disputa por interpretações e significados, e universalizaram uma linguagem de direitos que confere substrato à cultura. Sua jurisprudência aponta para a relevância de seu papel não como ator primário, mas como um dos espaços de interlocução entre os poderes públicos e a sociedade civil aptos a promoverem transformações sociais, mesmo em face de intensas reações populares. Nessa concepção, atores sociais marginalizados e informais adquirem legitimidade para visibilizar suas narrativas e pautar suas visões. A hipótese submetida à investigação neste trabalho é a de que os movimentos sociais atuam como coautores constitucionais por meio da esfera pública quando canalizados por um direito constitucional acessível e responsivo às releituras difusas na sociedade. Dentro de um modelo democrático deliberativo cujo valor epistêmico reside na participação argumentativamente qualificada de todos os interessados nos processos de tomada de decisão coletiva, os movimentos sociais são capazes de moldar a cultura constitucional e realizar política constitucional que gere transformações sociais por meio do questionamento e rearranjo de instituições e discursos sociais independentemente de rompimentos ou da energização esporádica de momentos fundacionais ou constitucionais. Nessa concepção, a política transformativa é operada pela participação cívica nos espaços e processos ordinários institucionais - como o judicial - e extra-institucionais - como a desobediência civil. A cultura de direitos, interpretações e significados constitucionais torna-se, portanto, uma moldura para a agência dos atores constitucionais.

Palavras-chave: Movimentos Sociais, Transformação Social, Backlash, Coautoria Constitucional, Constitucionalismo Democrático, Cultura Constitucional, Constitucionalismo Difuso, Democracia Deliberativa, Política Transformativa, Momentos Constitucionais. 


\begin{abstract}
Cançado Júnior, Hazenclever. Social Movements and Constitutional Co-authoring. 149 pages. Masters - Faculty of Law, University of São Paulo, 2018.

Constitutional Courts have established themselves as indisputable battlefields over interpretations and meanings, and universalized a language of rights that confers substrate to culture. Its jurisprudence points to the relevance of its role not as a primary actor, but rather as one of the spaces for dialogue between public branches and civil society capable of promoting change, even in the face of intense popular reactions. In this conception, marginalized and informal social actors acquire legitimacy to make their narratives visible and to rule their agendas. The hypothesis submitted to scrutiny in this research is that social movements act as constitutional coauthors through the public sphere when channeled by a constitutional law that is both accessible and responsive to diffuse re-readings in society. Within a deliberative democracy model whose epistemic value lies in the argumentatively qualified participation of all those interested in the processes of collective decision making, social movements are able to shape the constitutional culture and carry out constitutional politics that generates social transformations through the questioning and rearrangement of social institutions and discourses irrespective of ruptures or the sporadic energizing of foundational or constitutional moments. In this conception, transformative politics is operated by civic participation in ordinary institutions and processes - such as the judicial - and extra-institutional - such as civil disobedience. Thus, the culture of constitutional rights, interpretations and meanings becomes a framework for the agency of constitutional actors.
\end{abstract}

Keywords: Social Movements, Social Transformation, Backlash, Constitutional Coauthoring, Democratic Constitutionalism, Constitutional Culture, Diffuse Constitutionalism, Deliberative Democracy, Transformative Politics, Constitutional Moments. 


\section{AGRADECIMENTOS}

Expressar gratidão é despir-se. É abrir o peito e sair de si para reviver, recontar e revisitar. É celebrar o que se foi sem deixar partido, e o que se era sem ter perdido. Sempre com outros olhos, jamais sem esperança.

O nome solitário na capa desta dissertação transparece um inevitável fardo do pesquisador acadêmico, que, consumido por curiosidade e paixão, viu-se muitas vezes paralisado entre os custos e sacrifícios de um lado, e a satisfação e a realização de outro. Mas também esconde todo um cenário e uma imensidão de coautores que conferiram sentido a esses últimos três anos. Sem ambos, nem a primeira nem a última palavra teriam sido gravadas.

Agradeço ao meu Deus, minha realidade mais lúcida e vívida. Sua graça me concedeu o privilégio do encontro comigo mesmo. Ao vê-Lo, abracei quem sou e descobri para onde caminho. Seu amor já me permitiu alcançar muito além do que sonhei e, mais importante, me ensinou a viver uma vida plena, com olhos maravilhados colecionando belezas, enchendo pessoas de afeto e o mundo de sentido.

Agradeço a meu pai e a minha mãe por terem chorado e sorrido comigo nesses três anos. Carrego cada abraço de despedida e cada beijo de reencontro, porque eles me ensinaram a não ter nada por garantido. Nos dias mais difíceis e nas noites mais longas, encontrei neles uma rocha tão firme quanto amorosa. Se há algum mérito em mim ou no que faço, ele se deve ao inabalável encorajamento e à firme insistência que vocês têm em acreditar em mim. A graça que vocês me estendem é a mesma graça que tento replicar aos outros.

Agradeço às minhas irmãs, com quem formo meu mais bonito, afetuoso e sonhador mosaico de encontros. Somos parte constitutiva um do outro e não há um olhar para mim sem que se lhes veja. São elas quem me conhecem do avesso e me resgatam quando eu me escondo e me isolo. Somos tanto, que por vezes penso que é demais, mas nunca se esgota. Com elas compartilhei minhas maiores frustrações, medos e fracassos, e delas ouvi as palavras que me devolveram o fôlego.

Agradeço ao professor Conrado, meu orientador, que me ofereceu oportunidade para desenvolver esta pesquisa com liberdade criativa equilibrada com aconselhamentos precisos e convivência produtiva. Suas indicações de cursos e de leituras, suas críticas ao trabalho, as trocas em sala de aula e a colaboração em disciplinas da graduação foram fundamentais à minha consciência acadêmica e à 
formação da minha própria voz como pesquisador. O espaço ativo que me conferiu nas extensões e monitorias estão diretamente ligadas aos méritos deste trabalho e estou seguro de que reforçou em mim a paixão pelo ambiente acadêmico.

Agradeço ao professor Virgílio, um presente e disponível co-orientador informal, que também se tornou uma inspiração acadêmica tanto pelo rigor e lucidez com que escreve e participa de discussões, palestras e aulas, quanto pela acessibilidade e horizontalidade nas reuniões de grupos, seminários de pesquisa, seminários, monitorias, confraternizações. Seu incentivo a colocar todos os argumentos à prova e a superar os limites pessoais de exposição e de autoridade, bem como seu encorajamento a meus projetos pessoais, contribuíram massivamente para minha trajetória nesses últimos três anos.

Aos professores Conrado e Virgílio pela dedicação incansável à criação e ao estabelecimento de um ambiente acadêmico coletivo de construção de conhecimento e de colaboração em técnicas pedagógicas e de escrita, com seriedade, leveza e horizontalidade.

Ao grupo de pesquisa Constituição, Política \& Instituições, cujas reuniões, discussões e e seminários formaram em mim atitude crítica e postura acadêmica que me desenvolveram enquanto pesquisador, professor, aluno e pessoa. O envolvimento nas atividades do grupo e o contato com professores e colegas de todo o mundo ao longo de três anos me expuseram a toda sorte de ideias, concepções de mundo e formas de vida e manteve nutrido pelas novidades acadêmicas, além de desenvolver habilidades pedagógicas necessárias a um pesquisador e professor. Agradeço particularmente à Isadora Almeida, que com muita alegria e gentileza facilitou minha estadia em São Paulo no primeiro semestre de mestrado.

Às colegas de Pós-Graduação Clio Radomysler, Luiza Andrade, Lívia Guimarães, Carolina Marinho, Cecília Barreto e Rafael Bezerra Nunes, pelas trocas despretensiosas nos almoços coletivos, pela convivência em sala de aula, pelas leituras críticas e pelo exemplo acadêmico.

Aos colegas de Direito Constitucional Avançado, Rafael Bezerra Nunes, Pedro Arcain Riccetto, Ana Clara Pamplona e Filipe Gaspari, pela companhia às terças-feiras, por abraçarem esse desafio e por compartilharem todos os sonhos ainda em curso a respeito do futuro dessa extensão. 
A todos os alunos de Graduação com os quais tive contato em sala de aula em monitoria, extensões, palestras e seminários - por questionarem meus entendimentos e renovarem minhas concepções.

Às colegas do Núcleo Direito, Discriminação e Diversidade e do Departamento Jurídico XI de Agosto, cujos ensinamentos, questionamentos, reuniões e conversas me desconstruíram e me refizeram enquanto pesquisador, professor e, acima de tudo, como pessoa, deixando-me sempre atento e forte, jamais silente às discriminações, especialmente em ambientes universitários.

Aos colegas do grupo PósDebate, Rafael Bezerra Nunes, Túlio Jales e Pedro Arcain Riccetto, pela dedicação à manutenção de ambiente honesto e rigoroso de debate e crítica, mas sempre com espaço para bons encontros e divertida amizade.

Agradeço à genial professora Siri Gloppen, ao querido professor Bruce Wilson, ao talentoso professor Malcolm Langford, ao gentil professor Daniel Brinks e às excepcionais pesquisadoras Lara Côrtes, Luciana Gross Cunha e Martha Machado pelos ricos debates e generosas contribuições ao meu trabalho ao longo do curso $\mathrm{Ph} . \mathrm{D}$ Effects of Lawfare, na Universidade de Bergen, na Noruega. A imersão no maravilhoso, produtivo e desafiador ambiente acadêmico do Centre on Law \& Social Transformation no Chr. Michelsen Institute, foi determinante para os rumos desta pesquisa, não só pelas leituras e contatos pessoais, mas principalmente, pela amplitude e magnitude dos núcleos de pesquisa lá desenvolvidos, como Child Rights, Migration, Gender, Sexuality \& the Law, Inequality \& Effects of Law, Natural Resources \& Climate Warfare, Transitional Justice \& Legal Empowerment, etc., pela naturalidade das refeições em conjunto e pelo espírito comunitário criado dentro de casas, nas ruas e nos espaços comuns universitários, inclusive ao som de música brasileira. Agradeço aos colegas Patrícia Rezende, Ankit Bahtia, Jon Kåre Skiple, Mathilde Thorsen, Jana Belshner e Satang Nabaneh, pela convivência extremamente prazerosa e fértil durante minha estadia em Bergen e, ainda, pelas excepcionais conversas com Rashida Manjoo (former UN Special Rapporteur on Violence Against Women), Kathryn Sikkink (Harvard Univesity) e Howard Morrison (International Criminal Court), que plantaram em mim sonhos e me fizeram ter ainda mais convicção no caminho trilhado até aqui.

Aos membros da banca de qualificação e da banca examinadora, pelo aceite na participação, pela leitura atenta e crítica. 
Ao fundamental financiamento da bolsa CAPES, sem a qual minha permanência em São Paulo teria sido seriamente comprometida, e ao apoio de todos os funcionários da FDUSP.

Agradeço à Ana Beatriz Robalinho, pela parceria, companheirismo e verdadeira irmandade que superam as fronteiras do espaço-tempo e se aprofundam ano após ano. Acompanhar a desenvoltura de sua carreira acadêmica há quase dez anos nos permite debater ideias com franqueza, criticar argumentos com seriedade $\mathrm{e}$ fazer leituras atentas com rigor e colaborar na escrita com criatividade. Mas todas essas tarefas, por mais árduas e demandantes que sejam, tornam-se pequenas perto do significado que é vivenciar em conjunto diferentes experiências, nos Estados Unidos ou na Noruega, compartilhar sonhos, desenhar projetos, dividir choros e viver a vida ao lado um do outro com confiança, reciprocidade, alegria e bastante encorajamento.

Agradeço aos meus sete irmãos que, depois de 18 anos, ainda não sei se escolhi, se me escolheram, ou se Deus em sua bondade me deu. Eles engrandecem meus sonhos e celebram as pequenas vitórias. Nos fazemos em muitos e carregamos essa ânsia de viver tudo, esse anelo de estar e de ser, nada menos, nada mais. Como quem fecha numa gota o oceano.

Aos meus amigos Bilscoitos, dos quais recebo mais do que dou, o tempo só nos faz mais fortes, mais unidos, mais um. Ao amigo Antonio Borges, que tanto admiro e com quem divido minhas maiores simplicidades, meu abraço mais arrastado.

À Hillsong São Paulo e aos amigos (e irmãos) que ela me deu, por serem casa, abrigo, abraço, samba, fotografia e cozinha; por serem resistência, esperança, serviço, poesia e rua; por serem exposição, museu, show e festival; por serem fé, esperança e amor. Vocês me dividiram com a USP, Brasília e João Pinheiro, e ainda assim encontraram razão para permanecerem e lugar para ocuparem. Com vocês vivi São Paulo e embelezei o Centro. Por vocês eu sempre volto.

Este trabalho só faz sentido - no conteúdo, na forma, no espírito, nas razões e nos agradecimentos - porque pensado, refletido, vivido, cantado, declamado e escrito no plural. Só pelas afluências diretas de todos esses rios, mares e oceanos é que me enchi de energia, criatividade e resistência, tão mais necessárias de agora em diante.

“How beautous makind is! / O brave new world / That has such people in’t!". Agradecer por tudo isso é pouco. D'agora para frente, sigo assim: "não quero faca nem queijo. Quero a fome". "Fome de tudo - de conhecer por dentro - fome do miolo todo, do bagaço, da última gota de caldo". 
O presente trabalho foi realizado com apoio da Coordenação de Aperfeiçoamento de Pessoal de Nível Superior - Brasil (CAPES) - Código de Financiamento 001. 


\section{SUMÁRIO}

$\begin{array}{ll}\text { INTRODUÇÃO } & 15\end{array}$

$\begin{array}{ll}\text { Apresentação do tema e do problema } & 21\end{array}$

$\begin{array}{ll}\text { Estrutura do argumento e objetivos } & 24\end{array}$

CAPÍTULO 1: CORTES CONSTITUCIONAIS IMPORTAM 28

$\begin{array}{ll}1.1 \text { Introdução } & 28\end{array}$

1.2 Lawfare: cortes como arenas de disputa pela interpretação constitucional 29

$\begin{array}{ll}1.3 \text { Casos paradigmáticos de lawfare } & 37\end{array}$

1.3.1 Discriminação de raça 39

1.3.2 Discriminação de gênero 44

1.3.3 Direitos socioeconômicos 53

1.4 A política do backlash $\quad 57$

1.5 A resposta do constitucionalismo democrático 61

$\begin{array}{ll}1.6 \text { Desfecho } & 65\end{array}$

CAPÍTULO 2: MUDAÇA SOCIAL E A CONSOLIDAÇÃO DE UMA $\begin{array}{lr}\text { CULTURA CONSTITUCIONAL } & 67\end{array}$

$\begin{array}{ll}2.1 \text { Introdução } & 67\end{array}$

2.2 "Esperança vazia": a crítica ao desempenho das cortes na mudança social 68

$\begin{array}{ll}\text { 2.2.1 Mudança social significativa } & 73\end{array}$

2.2.2 Impacto na burocracia administrativa 76

2.2.3 Diálogo com minorias e grupos vulneráveis $\quad 80$

2.3 Interações entre cortes e sociedade civil $\quad 81$

2.4 A consolidação de uma cultura constitucional $\quad 87$

$\begin{array}{ll}2.5 \text { Desfecho } & 93\end{array}$

CAPÍTULO 3: EXPECTATIVA REDIRECIONADA: MOVIMENTOS SOCIAIS E COAUTORIA CONSTITUCIONAL 95

3.1 Introdução 95

3.2 A canalização dos movimentos sociais pelo direito constitucional 96

$\begin{array}{ll}3.3 \text { Reivindicação da autoria constitucional pela esfera pública política } & 100\end{array}$

3.4 Fundamentos democráticos de um constitucionalismo difuso 109

$\begin{array}{ll}3.5 \text { Desfecho } & 116\end{array}$ 
CAPÍTULO 4: PARÂMETROS PARA UMA POLÍTICA CONSTITUCIONAL TRANSFORMATIVA 118

$\begin{array}{ll}4.1 \text { Introdução } & 118\end{array}$

$\begin{array}{ll}4.2 \text { Política transformativa e momentos constitucionais } & 119\end{array}$

$\begin{array}{ll}\text { 4.3 A moldura da cultura constitucional } & 124\end{array}$

$\begin{array}{ll}\text { 4.4 Desafios à doutrina e à jurisdição constitucionais } & 128\end{array}$

$\begin{array}{ll}4.5 \text { Desfecho } & 131\end{array}$

$\begin{array}{lr}\text { CONCLUSÕES } & 133\end{array}$

$\begin{array}{ll}\text { BIBLIOGRAFIA } & 137\end{array}$

$\begin{array}{ll}\text { Material encontrado em sites } & 148\end{array}$ 


\section{INTRODUÇÃO}

"We inhabit a nomos - a normative universe."1

Os seres humanos não habitamos nem somos determinados apenas pelo visível e mensurável universo físico de massa, energia e tempo. Somos constituídos de moralidade, racionalidade e sociabilidade, e, a partir dessas perspectivas, criamos e mantemos, por uma série de estruturas, arranjos, discursos e convenções, universos de certo e errado, justo e injusto, bom e mau, válido e inválido.

Esses mundos normativos abrangem textos e prescrições legais e jurídicas indissociáveis das narrativas no tempo e no espaço que lhes dão interpretação, significado e concretude. Nessa intersecção entre dois universos nos quais habitamos, o direito é um tecido que nos envolve e ao qual damos forma e molde; ele é um dos principais mecanismos pelos quais conferimos sentido à realidade.

Esse processo de criação e concessão de significado opera essencialmente por meio da cultura e é coletivo, dialógico e combativo, mas nem sempre contínuo. Muitas vezes, o tecido é bruscamente rompido ou estendido ao limite; outras, é remendado. Mas alterações e reajustes acontecem e não podem ser completa nem previamente controlados. As narrativas em disputa - em âmbito privado e público são os fios que conduzem mudanças e, quando detentoras de força normativa, tornamse compromissos públicos e convenções sociais.

Historicamente, diversos textos adquiriram força normativa e tornaram-se epicentros de interpretação e significados: a Torá, o Código de Hamurabi, os Concílios do Vaticano, a Carta Magna, a Declaração Universal dos Direitos do Homem e do Cidadão, declarações nacionais de independência, etc.

Mais recentemente, constituições ao redor do mundo tornaram-se um desses compromissos públicos disputados - interpretados e reinterpretados, significados e ressignificados por agentes públicos e privados, mediante o uso da força ou não, e alguns formalmente alterados mais do que outros.

Mudanças culturais operam constantemente na sociedade. É provável que atualmente elas sejam mais rápidas e dinâmicas, impondo novos tipos de desafios e

\footnotetext{
${ }^{1}$ COVER: 1983. As civilizações grega e hebraica são reconhecidos exemplos do uso de narrativas para explorar questões normativas. Seus notórios legados jurídicos dizem mais respeito à variedade, riqueza e complexidade do universo normativo que criaram do que necessariamente à técnica ou retórica qualificadas no tratamento das questões políticas. Para
} 
dificuldades ao direito. Desde que o monopólio das cortes na interpretação constitucional foi questionado no contexto sócio-político e cultural do pós-guerra, mediante a emancipação de grupos sociais e o empoderamento de novos atores como legitimados a construírem suas próprias narrativas e expandirem o universo normativo, o tecido do direito tem sido disputado com novas ferramentas - como a linguagem de direitos humanos - e em novas arenas - como as cortes constitucionais.

The Times They Are A-Changing é uma canção composta por Bob Dylan em 1964 e mundialmente reproduzida e admirada. Na efervescência do movimento dos direitos civis nos Estados Unidos, da cultura de massa e dos meios de comunicação, da liberdade sexual e da emancipação (ainda que parcial) das mulheres, Dylan propôsse a escrever sobre as profundas mudanças sociais em desdobramento.

Como qualquer texto escrito, sua interpretação é aberta e passível de disputa. Em leitura própria, ilustro que as estrofes da canção dialogam diretamente com as relações entre mudança cultural, mudança social e mudança jurídico-legal que aqui se pretende analisar.

"Come gather 'round people Wherever you roam And admit that the waters Around you have grown And accept it that soon You'll be drenched to the bone. If your time to you Is worth savin' Then you better start swimmin' Or you'll sink like a stone For the times they are a-changin'."

Dylan alerta para uma mudança em curso nas águas, isso é, em comportamentos, discursos e visões de mundo - elas estão subindo ao redor de nós e a resistência em aceitá-las só nos fará afogar. Se resistirmos às mudanças, afundaremos como pedras duras, impenetráveis e inflexíveis, mas se as aceitarmos, melhor que comecemos a nadar (a favor da maré).

"Come writers and critics Who prophesize with your pen And keep your eyes wide The chance won't come again And don't speak too soon For the wheel's still in spin 
And there's no tellin' who

That it's namin'

For the loser now

Will be later to win

For the times they are a-changin'."

Àqueles que têm o poder da caneta, de conferir sentidos e interpretações, ditar rumos e dizer o futuro - aos juízes e cortes, às instituições - Dylan recomenda a vívida atenção ao movimento das águas para que não se movam demasiadamente lento, porque a chance para salvar-se pode não vir duas vezes, nem se antecipem abruptamente, porque as ondas ainda estão tomando forma e a roda ainda está tomando direção. Nesse erro de cálculo e de leitura do curso das águas, aquele ator ou aquela instituição que propõe-se a dar o rumo pela palavra, ainda que pareça vencedora, pode sofrer severa derrota logo em seguida.

"Come senators, congressman

Please heel the call

Don't stand in the doorway

Don't block up the hall

For he that gets hurt

Will be he who has stalled

There's a battle outside

And it's ragin'

It'll soon shake your windows

And rattle your walls

For the times they are a-changin'."

Aqui, dirige-se aos representantes eleitos, àqueles naturalmente sensíveis às águas e suas turbulências: há uma disputa acontecendo além de suas próprias arenas e logo ela lhes baterá à porta, mas não necessariamente de forma sutil. Então, que não criem bloqueios ou obstáculos ao que virá.

"Come mothers and fathers

Throughout the land

And don't criticize

What you can't understand

Your sons and your daughters

Are beyond your command

Your old road is

Rapidly agin'

Please get out of the new one

If you can't lend your hand For the times they are a-changin'." 
Mudanças culturais operam também no âmbito privado e tomam forma entre gerações. É como se as mais novas constantemente pressionassem as mais velhas nas quais se inserem os poderes e instituições públicas - à crítica, à reformulação, à desconstrução e à reconstrução. É como se o novo sempre viesse, como na canção de Belchior $^{2}$, e, nesse caso, melhor que o deixem passar.

"The line it is drawn

The curse it is cast

The slow one now

Will later be fast

As the present now

Will later be past

The order is

Rapidly fadin'

And the first one now

Will be last

For the times they are a-changin'."

A última estrofe parece enfatizar não só que as configurações e ordens sociais mudam ou desaparecem, mas também que agentes interpretativos e decisórios são eles próprios removidos ou substituídos.

As mudanças sociais acontecem a partir de conflitos de forças que se dão, inclusive e mais recentemente com bastante repercussão e consequências, em arenas judiciais. $\mathrm{O}$ mundo normativo em que vivemos é, hoje, profundamente atravessado pelos significados que atribuímos por meio do direito.

A direção dessas transformações não pode ser prevista nem controlada. Ainda que existam defensores de um progressismo moral da história inescapavelmente determinista, nem todas as mudanças podem ser consideradas benéficas; reconfigurações de poder e novos vencedores surgem em variados contextos sociais tanto para expandir quanto para restringir as interpretações de conceitos e direitos como liberdade e igualdade.

Prova disso são contextos políticos autoritários onde o constitucionalismo não funciona propriamente. Benvindo (2017:206-2011) faz crítica interessante ao dizer que as categorias paradigmáticas da democracia constitucional nos seduzem por suas potencialidades de promover novos futuros, levando-nos ao limite de defendê-las mesmo em face de seus próprios rompimentos. $\mathrm{Na}$ aplicação dessas categorias (deliberação, participação e liberdade de expressão, por exemplo) há diversas

\footnotetext{
${ }^{2}$ Como Nossos Pais, de 1976.
} 
fragilidades que podem subverter uma ordem constitucional em direção abusiva e autoritária, quando não lidas dentro de um amplo quadro socioeconômico e cultural. ${ }^{3}$

Particularmente no Brasil, a Constituição de 1988 instaurou uma ordem democrática cujas autoria normativa foi diretamente reivindicada por grupos sociais excluídos ou marginalizados.

A esse respeito, James Holston (2015) desenvolve belíssima pesquisa acerca da apropriação e ressignificação do conceito jurídico "cidadania" pela periferia urbana brasileira, com foco empírico na cidade de São Paulo. Antes de 1988, a lei era instrumento de humilhação, medida por burocracia inacessível e refletia hierarquia: às elites, tudo; aos pobres, aos invasores, aos (i)migrantes e aos grevistas, o rigor da lei. Os novos métodos de participação e mobilização cívica a partir dos anos 80 contribuíram diretamente para a compreensão coletiva de que as necessidades socioeconômicas básicas poderiam ser repensadas na linguagem dos direitos humanos, culminando na participação maciça e sem precedentes no processo constituinte ${ }^{4}$.

Para além do formalismo democrático, a articulação popular se organizou e se educou em torno da construção estratégica de normas que incluíssem na agenda da Assembleia Nacional Constituinte demandas de iniciativas populares, inclusive para monitorar a aprovação de seus projetos. Holston enfatiza que a participação cívica de grupos vulneráveis gerou uma transformação da cidadania que partiu dos níveis locais em direção ao nacional: práticas locais de atores sociais marginalizados e tradicionalmente excluídos tornaram-se fontes de direito constitucional

Esse processo de criação de novos entendimentos e práticas acerca dos direitos deixou marcas profundas no imaginário coletivo e social brasileiro e tornou-se responsável por uma verdadeira formação de cultura constitucional. Nas entrevistas conduzidas por Holston com moradores de periferias urbanas, grande parte da

\footnotetext{
${ }^{3}$ Em leitura crítica da narrativa de Joshua Braver sobre a criação da Constituição de 1999 na Venezuela, Benvindo defende a interpretação do constitucionalismo inclusive por suas falhas, sem a sedução da confiança em seus pontos fortes. Isso se dará somente dentro de um quadro maior que considera os fatores econômicos, sociais e culturais que permeiam aquela sociedade. Esses sistemas constitucionais disruptivos devem ser lidos e analisados à luz de suas práticas de restrição democrática; para isso, Benvindo faz menção de categorizações como abusive constitutionalism e stealth constitutionalism.

${ }^{4}$ A organização nacional da iniciativa popular na elaboração do texto constitucional se deu majoritariamente por meio do Movimento Nacional pela Participação Popular na Constituinte (Rio de Janeiro, 1985) e do Plenário Pró-Participação Popular na Constituinte (São Paulo, 1985). A esse respeito, ver Michiles e outros (1989).
} 
consciência de direitos se deu pela auto-identificação como destinatário do texto constitucional escrito:

"Mas hoje eu penso o seguinte: eu tenho direitos porque a Constituinte [a Constituição] me dá esses direitos. Mas eu tenho que correr atrás dos meus direitos, porque se eu não for correr atrás dos meus direitos, eles não vão cair do céu. (...)" Morador do Jardim das Camélias desde 1970, trabalhador da indústria têxtil aposentado (Holston 2015:340-341)

“Antes de 1988, não era escrito, não era claro. Antigamente você falava: eu tenho direito, mas não estava comprovado em lei na Constituição. (...) Hoje está em lei tudo aquilo que eu posso fazer. Hoje você tem um livro [a Constituição] que você pode ir lá ver, olha, eu posso fazer isso, posso fazer aquilo. (...) A Constituinte fala mais direito, o direito assim, mais do cidadão mesmo. A lei está escrita. Eu posso ali pesquisar na lei. Olha, eu posso estar usufruindo desse bem." Moradora de segunda geração do Lar Nacional (Holston 2015:340-341)

"Eu acho que por mais analfabeto que seja a pessoa, tem que saber os seus direitos na Constituinte. Tem dúvida, tem lá, a lei do País, a Constituinte [a Constituição]. Você tem que chegar lá e ler o que significa. Não sabe, procura uma pessoa que sabe. [...] É o conhecimento da Constituição que dá esse direito para você lutar pelos seus direitos." Morador pioneiro do Jardim das Camélias (Holston 2015:340-341)

A prévia cultura de deferência e inércia foi frontalmente desafiada pela mobilização social que resultou na participação ativa do processo constituinte e na construção de uma cultura constitucional de direitos escritos, a qual serviu posteriormente às lutas sociais por sua realização e satisfação.

Nas últimas décadas, as mobilizações procuraram reivindicar judicialmente a aplicação do texto escrito para suas realidades e configurações sociais, pressupondo a totalidade dos direitos possíveis. A judicialização dos direitos sociais, a luta pelo reconhecimento de identidades e o combate a privilégios passaram a pautar a agenda de políticas públicas e das cortes, aprofundando a divisão social acerca das interpretações e significados constitucionais.

Ao mesmo tempo em que narrativas antes marginalizadas costuram e visibilizam novos discursos e interpretações constitucionais, parlamentos restam 
paralisados diante da complexidade da realidade e sem saber como oferecer as respostas formais adequadas, e as cortes agigantam-se como bastiões iluministas e paternalistas das sociedades.

Essa reconfiguração tem sido reproduzida em diferentes sistemas políticos e ordenamentos constitucionais no mundo, segundo suas particularidades, fazendo quase que universais os desafios impostos pela realidade ao direito constitucional.

\section{Apresentação do tema e do problema}

Nesse jogo político que disputa a interpretação constitucional, a frente de batalha foi majoritariamente transferida para uma nova arena: as cortes constitucionais. Movimentos sociais - ligados a partidos ou não - apropriaram-se da linguagem dos direitos e voltaram-se às cortes para avançarem suas agendas.

O cânone constitucional tradicional é constituído pelo texto constitucional e por suas emendas oficiais, as quais expressam as mudanças na identidade constitucional. Contudo, parte significativa das conquistas constitucionais das últimas décadas se deu fora do locus formal da política constitucional. Pergunta fundamental sobre a qual essa pesquisa se debruça é: que ferramentas a teoria constitucional tem oferecido para dar conta dos episódios históricos de mudança constitucional informal a partir das mobilizações sociais que têm se tornado cada vez mais frequentes, impactantes e naturalizados em diferentes sistemas constitucionais?

A literatura predominante no direito constitucional concentra-se na figura do juiz - seu comportamento individual e coletivo, suas técnicas de decisão e sua argumentação - tanto para explicar as razões, vantagens e eficácia de sua atuação hercúlea na garantia e promoção das liberdades civis e dos direitos constitucionais básicos como saúde, educação e moradia, quanto para criticar sua politização, sua parcialidade e seu agigantamento em face dos demais poderes.

Essa racionalização, contudo, distorce a realidade ao desconsiderar a performance estratégica de diversos atores constitucionais na condução da interpretação judicial da linguagem de textura aberta das garantias constitucionais. Fenômenos como o de facto ERA, a incorporação das Cartas de Direitos pelos sistemas constitucionais regidos pelo direito comum e a judicialização dos direitos 
sociais não são suficientemente explicados por mera interpretação judicial, processo legislativo e de emendamento constitucional.

Partindo desse problema, este estudo pretende analisar as possibilidades e potencialidades de os cidadãos coletivamente reivindicarem a autoria do direito constitucional por meio da consolidação de uma cultura constitucional a que os poderes públicos em geral e as cortes constitucionais em particular devam deferência, responsividade e accountability ao realizarem política constitucional.

Os processos de tomada de decisão coletiva não operam no vácuo, na literalidade do cânone constitucional tradicional nem em completa dissonância com os demais atores. Eles são inseridos numa moldura de princípios, precedentes e valores aqui entendida como cultura constitucional.

A investigação de decisões de cortes constitucionais ao redor do mundo certifica o papel crescente dos movimentos sociais enquanto agentes interpretativos na perseguição de seus objetivos por meio da instrumentalização do direito. Para além de protestos e desobediência civil, as últimas décadas assistiram à tomada do processo constitucional e das emendas constitucionais como instrumentos de batalha.

Por meio da identificação das principais conquistas de direitos com participação dos movimentos sociais na história constitucional dos Estados Unidos onde esse fenômeno acontece por mais tempo e com mais destaque e escrutínio - e de democracias recentes como Brasil, Colômbia e África do Sul, a pesquisa buscará entender como se operam a mudança social e a conquista de direitos dentro do arranjo contemporâneo da separação de poderes.

No caminho, serão analisados os reveses enfrentados por essas decisões e a interação política das cortes com os poderes representativos em contextos na disputa pela interpretação constitucional. Quando o poder público se desacopla da visão constitucional predominante na sociedade civil - seja pelo desembaraço em acelerar demais a engrenagem, seja pela letargia em ler e acompanhar as mudanças que na sociedade se operam -, o natural é que haja uma imediata e vigorosa reação popular ${ }^{5}$.

\footnotetext{
${ }^{5}$ A convocação de reações populares pode vir, inclusive, da própria corte constitucional. Em Lawrece v. Texas (2003), o juiz Antonin Scalia deixou claro em sua opinião que autorizar o casamento gay no estado texano seria gradualmente estendido à nação norte-americana, a não ser que emergisse intensa mobilização contra a decisão da Corte. Em poucos dias a contramobilização estava organizada, inclusive para pedir o impeachment dos juízes favoráveis.
} 
As críticas acadêmicas à capacidade de inovação e à habilidade das cortes em promoverem mudanças serão igualmente consideradas, a fim de que se aponte uma saída a essa trincheira dualística se cabe ou não às cortes responderem a tais demandas ou se há impacto ou não em suas decisões.

Como parte considerável da política constitucional tem ocorrido a partir da jurisdição constitucional, é natural que os poderes públicos e demais instituições reajam a um progressismo liberal que ameaça o establishment de maiorias políticas e elites tradicionalistas, polarizando discursos e levando partidos políticos a lados extremos do espectro político.

O que se segue - e se tem visto ao investigar diferentes sistemas nacionais - é o aprofundamento da divisão social, a extremização dos discursos políticos e a retração de cada instituição para dentro de seu próprio modus operandi; cortes, parlamentos e executivos permanecem demasiadamente preocupados com a reafirmação da própria legitimidade e capital, e pouco dialogam entre si, não obstante sofram influências mútuas a todo tempo. Suas forças parecem mais concentradas em conquistar a opinião pública, cada um a seu modo, intensificando as ondas de reações populares.

Nesse campo onde ainda há tantos espaços de atuação para serem conquistados e de diálogo a serem construídos, este estudo propõe-se a encontrar esperança no engajamento cívico e na deliberação coletiva dos indivíduos. Se a era constitucional dos direitos foi implantada por uma nova configuração da relação política indivíduo-sociedade, a democratização de seu acesso se dará por sua organização de dentro para fora.

A interação dos grupos sociais com o poder público para além do processo formal pressupõe um engajamento participativo em deliberação coletiva que compõe substrato fundamental do próprio princípio democrático. Por meio da deliberação constitucional, grupos, movimentos, instituições e comunidades expressam suas identidades e reivindicam valores constitucionais.

Essa participação popular oferece um meio criativo de responsividade democrática, comumente associada às práticas formais de mudança constitucional em momentos de crise ou transição. O instituto da soberania popular sobre o qual assentam a constituição e o Estado democrático de direito não pode limitar-se à fundação da ordem constitucional, mas deve ser contínua e intergeracionalmente re- 
apropriada pela interação entre cidadãos e instituições, que exige, como se verá ao longo dos próximos capítulos, o recrutamento de novas vozes, a organização em grupos, a acomodação de visões contrárias, o alcance da mídia e a influência em alguma instituição.

\section{Estrutura do argumento e objetivos}

A pesquisa que resultou neste trabalho funda-se primariamente em três problemáticos diagnósticos:

(i) o agigantamento da jurisdição constitucional nos mais diferentes sistemas constitucionais - da América Latina à África do Sul, da Europa Oriental à Índia, do commonwealth britânico a Israel. Em todos esses contextos, as cortes assumiram proeminência no arranjo institucional e na política constitucional, conferida ou não por uma Carta de Direitos que viabilize uma jurisdição mais ativa ao estilo norteamericano. Para além da regra da maioria, o governo democrático pressupõe um genuíno compromisso com direitos individuais fundamentais entrincheirados na tentativa de salvaguardar grupos vulneráveis, o que abre caminho para a crença em mudança social a partir de direitos judicialmente afirmados. ${ }^{6}$

(ii) a ascendente relevância dos movimentos constitucionais no jogo político. Movimentos são construções sociais de crenças e objetivos plurais que organizam suas ações na correlação orientações-oportunidades (MELUCCI 1985). Organizar coletivamente indivíduos e mantê-los mobilizados demandam alocação de recursos, valores e capacidades. No novo espaço da esfera pública política, o objetivo não é necessariamente transformar os movimentos sociais em partidos políticos, mas ecoar suas mensagens na sociedade e traduzi-las em tomada de decisão política. O poder simbólico da ação coletiva tem desafiado a lógica da distribuição de poder entre as elites e a fragilidade de suas razões de ser. Antes de serem capazes de negociar valores e disputar interpretações, os movimentos sociais procuraram ultrapassar a invisibilidade e jogar luz sobre a neutralidade da dominação econômica ou cultural. Nada manteve-se inquestionável; pela primeira vez, as sociedades em geral tornaram-

\footnotetext{
${ }^{6}$ Ronald Dworkin é talvez o mais proeminente teórico a sustentar normativamente o constitucionalismo e a jurisdição constitucional. As questões e dissensos referentes às condições democráticas são respondidas por um desenho institucional voltado ao resultado, e não ao procedimento. A esse respeito, ver Dworkin (1977, 1985 e 1986).
} 
se conscientes de sua contingência. A autoridade da constituição é reivindicada e ratificada pelas interações substantivas provocadas pelos movimentos sociais.

(iii) o fetichismo institucional da análise jurídica em torno dos juízes e das cortes constitucionais. Conquanto sejam largamente defendidas como barreira de contenção majoritária ${ }^{7}$, as cortes não são capazes de por si só emanciparem os indivíduos e grupos vulneráveis ou de desenvolverem materialmente a sociedade. Destituído da bolsa e da espada (Madison 1993 [1787]), o Judiciário mostra-se incapaz de absorver e traduzir todos os ecos e irritações provenientes da sociedade civil. Seus procedimentos e linguagens podem mais afastar do que aproximar aqueles que deveriam ser protagonistas da disputa constitucional. A replicação do sistema norte-americano parece congelar a dimensão criativa do direito constitucional, reduzindo os resultados que ele pode produzir aos resultados que os juízes e cortes podem produzir.

Esse cenário deu causa a algumas perguntas incidentais que me permitem desenvolver a pesquisa: quais as origens dessa intensa judicialização dos interesses, disputas e narrativas políticas e a quem ela interessa? Quais os atores legitimados a atuarem nas esferas institucionais de disputa constitucional e, portanto, aptos a produzirem reformas constitucionais? Por quê ou como eles obtêm êxito? Em que medida a utilização da linguagem dos direitos e eventualmente das cortes contribui para uma efetiva mudança social ou reformas em termos de proteção e concretização de direitos?

Revisar a literatura que me permite enfrentar esses questionamentos na trajetória deste trabalho oferecerá suporte factual para as reflexões normativas da pesquisa propriamente ditas. As perguntas primárias a que se pretende responder, pois, são: de que maneira(s) ou por meio de quais ferramentas o direito constitucional consegue responder às mudanças sociais intermitentes que se operam nas sociedades contemporâneas? A legitimação das mobilizações populares como coatores constitucionais auto-interessados confere um quadro normativo à maximização da democracia constitucional?

\footnotetext{
${ }^{7}$ Para uma síntese desses autores, conferir Mendes (2008:55-77). Os principais argumentos a favor da supremacia judicial assentam-se na afirmação de que cortes protegem as précondições da democracia e os direitos das minorias, são menos falíveis em questões de princípios, promovem representação deliberativa e argumentativa e constituem veto à separação de poderes. De outro ângulo, defende-se a supremacia judicial ao criticar o parlamento como único tipo possível de representação e a racionalidade da regra da maioria.
} 
Procuro contribuir para o enfrentamento dessas questões por meio de três argumentos principais, reunidos nos próximos capítulos.

Inicialmente, pretendo afirmar o litígio estratégico como instrumento relevante de disputa pela interpretação constitucional. No primeiro capítulo, faço uma retrospectiva de casos constitucionais de sucesso nos quais os movimentos sociais conseguiram pautar o debate e avançar sua agenda por meio do uso do papel contramajoritário das cortes. Aqui, respondo a alguns reveses que sucederam à tomada de decisão judicial em razão da formação de uma política de backlash que desafia a autoridade das cortes e a implementação de suas decisões.

Em seguida, proponho-me a enfrentar as principais críticas à capacidade institucional das cortes de promoverem mudança e gerarem impacto social. $\mathrm{O}$ argumento sustentado por Gerald Rosenberg (1991) de que as cortes constitucionais oferecem uma esperança vazia parece desconsiderar ou, no mínimo, subestimar aspectos relevantes da interação que se dá no diálogo entre corte e sociedade civil no processo de tomada de decisão. Fecho o segundo capítulo em defesa da consolidação de uma cultura constitucional que funcione como uma moldura mais larga do que o cânone tradicional do direito constitucional para as cortes constitucionais se comportarem e construírem sua jurisprudência.

No capítulo três, discuto as razões e os benefícios em se redirecionar a expectativa social para o engajamento cívico e a ação coletiva, de tal sorte que conquistem cada vez mais espaço na cultura constitucional e mais sucesso como atores constitucionais. Para tanto, dedico-me à leitura crítica de teóricos do direito e das ciências sociais para expandir o cânone do direito constitucional, legitimar atores constitucionais antes periféricos e retirar não só a exclusividade da palavra das cortes em casos difíceis, como defendido por muitos teóricos constitucionais ao redor do mundo $^{8}$, mas também dos juízes a centralidade na racionalização em torno dos direitos fundamentais.

\footnotetext{
${ }^{8}$ Jeremy Waldron é certamente o autor que mais se destaca nessa tese, mas vale conferir também as visões e argumentos de Sunstein (2001), Rosenberg (1991) e Tushnet (1995). Em geral, essa defesa sustenta-se nos valores da representação eleitoral e da regra da maioria. O primeiro desdobra-se na crença de que o parlamento representativo é o mais próximo do ideal de manifestação popular e organiza-se em um processo que estimula a competição, o compromisso e a acomodação de extremos. O segundo, por sua vez, além de respeitar a força moral da igualdade, limita o poder. Contra a dominação das cortes no embate com o Legislativo pesam a ausência de imparcialidade, de representatividade e de meios de
} 
Por fim, o capítulo quatro pretende pensar as possibilidades de um direito constitucional acessível a novos atores constitucionais e aberto às dinâmicas e interações sociais. Essa configuração é viabilizada por uma cultura constitucional coletivamente construída e respeitada pelos poderes públicos. Nela, qual seja a arena ou frente de batalha escolhida na aferição de significado constitucional, haverá espaço e oportunidade para impacto e mudança social por meio da conquista de direitos na vida comum daqueles que antes se viam excluídos e sub-representados no jogo constitucional. Argumento que essa é a realização epistêmica de um modelo de democracia deliberativa por meio de um constitucionalismo difuso que permite o rearranjo de instituições e discursos sociais em momentos de energização social dentro da política ordinária.

implementação; a falibilidade em questões de princípios, a incapacidade educativa e a inevitabilidade da tirania. Para essa sintetização, conferir Mendes (2008:78-96). 


\section{CONCLUSÕES}

O discurso constitucional tem corrido como um rio das salas de audiências e de julgamentos das cortes para a sociedade civil, cujos espaços são preenchidos por uma cultura compartilhada de direitos derivados de um texto que permanece sob disputa. O caso emblemático do jovem que ergueu cópia da Constituição de 1988 feito arma em manifestação popular na Avenida Rio Branco em São Paulo (Gomes 2016:167) comprova o empoderamento de pessoas comuns que se sentem capazes de apropriar-se do texto e reivindicar suas causas por meio da política constitucional.

Nesse cenário, o lawfare consolida-se como meio de canalização desses conflitos pela linguagem dos direitos que possibilitou novas leituras do texto constitucional e o reaproximou de novos significados e interpretações. Enquanto estratégia mais ampla de promoção ou retração de mudança social, o uso da litigância constitucional confere força normativa aos compromissos políticos e valores que norteiam a interpretação constitucional e codifica as disputas em uma linguagem de direitos que acrescenta simbolismo, visibilidade e expressividade a narrativas marginalizadas.

Tudo isso prepara terreno para apoio midiático e político-partidário, impondo constrangimento às instituições a tomarem decisão. Lawfare importa, portanto. A ilustração desenvolvia ao longo do primeiro capítulo demonstra como a construção de uma jurisprudência em torno dos direitos à igualdade de raça, de gênero e à concretização de direitos socioeconômicos reforçou todos os benefícios simbólicos e normativos e demonstrou a relevância da atuação dos movimentos sociais como instância da sociedade civil organizada. Suas mobilizações revestem-se de forças e fraquezas, que demandam um manuseio instrumental e incremental da política do backlash dentro de um projeto constitucional inclusivo às interpretações e ressignificações difusas na sociedade.

Ressaltado o papel das cortes como arena de disputa por direitos constitucionais, os juízes saem dos holofotes como agentes interpretativos primários, abrindo espaço para novos atores que se utilizam do processo e da linguagem constitucionais dentro e fora das cortes. Se essas não podem levar a cabo transformação social por si sós, há que se redirecionar as expectativas para o 
engajamento cívico dos cidadãos organizados, que atuam diretamente na reivindicação de direitos e na moldagem da cultura constitucional daquela comunidade política, formada pelos valores e símbolos mais fundamentais.

Trata-se de uma cultura que protege valores e realiza outros, mas que encontra necessariamente correspondência com as visões que prevalecem na sociedade. Essa cultura envolve práticas e papeis sociais que orientam as interações entre cidadãos e instituições a respeito dos significados constitucionais. A adoção de uma interpretação se dará, portanto, dentro dessas interações, cuja moldura é a própria cultura constitucional.

A consciência coletiva de direitos e a atuação da sociedade civil no quadro normativo da cultura constitucional traduzem as experiências excluídas, as violências, abusos e privações do mundo da vida em injustiças, depositando expectativas na participação coletiva na política constitucional para que haja transformação social por meio do questionamento de discursos e rearranjo de instituições.

Dentre as principais origens desse processo explicadas nesta dissertação estão a sedução argumentativa da linguagem dos direitos e a crescente articulação dos movimentos sociais em regimes democráticos com forte operação das cortes. A opção pela litigância constitucional nem sempre foi bem sucedida ou de fato provocou transformação social; em muitas ocasiões, na verdade, provocaram intensas reações sociais e a organização de backlashes que a neutralizassem ou superassem.

No entanto, foi demonstrado ao longo do trabalho que, dentre outros efeitos, ela abriu espaço para um novo tipo de constitucionalismo que considerasse as releituras cotidianas do texto constitucional pelo cidadão comum e legitimasse sua atuação coletiva como coautora de novos significados constitucionais.

A partir disso, retomo de forma tópica as conclusões da pesquisa apresentadas ao longo do trabalho:

(i) A sociedade civil se engaja em disputas interpretativas pela ressignificação do texto constitucional à luz de suas próprias experiências e vivências por meio de diversos sujeitos individuais e coletivos que interagem argumentativamente nos espaços públicos e privados. Essa atualização do texto constitucional reflete a tensão entre constitucionalismo e democracia, na medida em que confere estabilidade à ordem democrática ao mesmo tempo em que se abre para amplas reinterpretações. 
(ii) A obsessão institucional da análise jurídica em torno das cortes constitucionais como agentes primários de interpretação ou detentores da palavra final mascara a compreensão do papel desempenhado pelos movimentos sociais na promoção de mudança social, aqui entendida como virada normativa ou material.

(iii) A escolha dos movimentos sociais pela litigância constitucional é apenas uma de suas estratégias. Contudo, ela cumpre seu papel na prática do lawfare, cujos benefícios superam os riscos de backlash. Decisões judiciais que pautam agendas dos movimentos sociais criam ônus argumentativo e custo político às tentativas de reversão, e educam os próprios litigantes na linguagem dos direitos. Uma vez que estão carregadas de valor simbólico que expressam a lógica e o espírito da constituição, essas decisões abrem-se à responsividade às necessidades sociais das minorias e grupos vulneráveis e apresentam grande potencial de implementação a partir do reforço de seu caráter dialógico com a justiça administrativa.

(iv) Nesse contexto interativo entre sociedade civil e Estado a respeito de normas constitucionais que expressam concepções morais e compromissos políticos, desenvolve-se uma linguagem única entre diferentes atores e instituições, manifestada na consciência coletiva de direitos, cujo conteúdo interno e limites externos permanecem sob reformulação dinâmica e inconclusa. A complexidade das sociedades tem expandido essa cultura na medida em que ela se abre para a participação coautoral desses novos atores constitucionais.

(v) Os movimentos sociais se organizaram teórica e materialmente de tal forma que se provaram bem-sucedidos em realizar política constitucional, na medida em que questionaram culturas e discursos dominantes, conferiram visibilidade às narrativas e formas de vida de minorias excluídas do processo político, e traduziram injustiças à linguagem da cultura constitucional. Constituíram-se, pois, como engrenagem relevante na solidariedade social a partir de um sentimento de autoria constitucional e colaboraram para a energização da sociedade na esfera pública política independentemente da ocorrência de eventos emergenciais ou momentos extraordinários de criatividade institucional.

(vi) Além dos caminhos oficiais de conformação do sentido constitucional a seus objetivos, os movimentos sociais atuam estrategicamente por meios extrainstitucionais, como a mutação constitucional e a desobediência civil. Essa atuação informal contundente demanda um constitucionalismo responsivo às releituras difusas 
que as legitime nos espaços públicos e privados; democrático no acesso desses novos atores à informação e ao processo constitucional por meio de práticas institucionais e mecanismos participativos; e capaz de endereçar normativamente a posição e o papel dos movimentos sociais por meio da cultura constitucional.

Esse constitucionalismo reconhece os rearranjos discursivos e institucionais conduzidos pelos movimentos sociais e reafirma sua atuação na diminuição dos espaços temporais em que se realiza política constitucional transformativa, inclusive pelos efeitos indiretos e a longo prazo das mobilizações de massa.

(vii) A configuração dos movimentos sociais como coautores constitucionais explora as tensões entre constitucionalismo e democracia e legitima seus entendimentos constitucionais cotidianos como primordiais nos fóruns de debate coletivo. Uma vez canalizada essa configuração por um direito constitucional difuso, os movimentos sociais tornam-se legítimos e aptos a produzirem transformações sociais por meio do questionamento e do rearranjo de instituições e discursos sociais de forma independente de rompimentos ou da energização esporádica de momentos fundacionais ou constitucionais.

Nessa concepção, a política transformativa é operada pela participação cívica nos espaços e processos ordinários institucionais - como o judicial - e extrainstitucionais - como a desobediência civil. A cultura de direitos, interpretações e significados constitucionais torna-se, portanto, uma moldura para a agência dos atores constitucionais.

Em última instância, o que se propõe é uma adesão ao modelo democrático deliberativo cujo valor epistêmico resida na participação argumentativamente qualificada de todos os interessados nos processos de decisão coletiva. Nesse framework, o texto constitucional deixa de ser mera promessa de futuro ou carta de intenções e abre-se à disputa inclusiva e amplamente participativa pela conquista e reformulação de direitos, segundo as necessidades sociais do tempo-espaço. 


\section{BIBLIOGRAFIA}

Ackerman, Bruce (1991). We the People: Foundations. Cambridge \& London: Harvard University Press.

Ackerman, Bruce / James S Fishkin (2004). Deliberation Day. New Haven \& London: Yale University Press.

Ackerman, Bruce (2007). “The Living Constitution”, Harvard Law Review, 120(7).

Ackerman, Bruce (2014). We the People: the civil rights revolution. Cambridge, Mass: The Belknap Press of Harvard University Press.

Albert, Richard (2013). "The Expressive Function of Constitutional Amendment Rules", McGill Law Journal 225(59).

Amar, Akhil Reed (2012). America's Unwritten Constitution: The Precedents and Principles We Live By, New York: Basic Books.

Andersen, Ellen Ann. (2005). Out of the Closets and into the Courts: Legal Opportunity Structure and Gay Rights Litigation. Ann Arbor, MI: University of Michigan Press.

Balkin, Jack M. (1995). "Populism and Progressivism as Constitutional Categories", The Yale Law Journal, 104(7).

Balkin, Jack M. / Sanford Levinson (1998). "The Canons of Constitutional Law", Harvard Law Review, 111(4).

Balkin, Jack M. / Sanford Levinson (2001). "Understanding the Constitutional Revolution”, Faculty Scholarship Series, 249.

Balkin, Jack M. (2004). "What Brown Teaches Us About Movements and the Law: the case of affirmative action". Virginia Law Review, 90(6).

Balkin, Jack M. (2005). "How Social Movements Change (or Fail to Change) the Constitution: The Case of the New Departure", Faculty Scholarship Series. 235. 
Balkin, Jack M. / Reva B. Siegel (2006). "Principles, Practices, and Social Movements", University of Pennsylvania Law Review, 154(4).

Balkin,Jack M. (2009). “Critical Legal Theory Today”, in Francis Jay Mootz (ed). On Philosophy in American Law, Cambridge University Press.

Balkin, Jack M. (2011). Living Originalism. Cambridge, Mass.: The Belknap Press of Harvard University Press.

Barber, Sotirios (1984). On What the Constitution Means, The Johns Hopkins University Press.

Barroso, Luís Roberto (2011). "Constituição, Democracia e Supremacia Judicial: Direito e Política no Brasil Contemporâneo", Atualidades Jurídicas: Revista do Conselho Federal da Ordem dos Advogados do Brasil, 1(1).

Benvindo, Juliano Zaiden (2015). "The Seeds of Change: Popular Protests as Constitutional Moments". Marquete Law Review 99(2).

Benvindo, Juliano Zaiden (2017). “'Revolutionary Reform' and the Seduction of Constitutionalism" in Richard Albert / Xenophon Contiades / Alkmene Fotiadou. (eds). The Foundations and Traditions of Constitutional Amendment. Oxford and Portland, Oregon: Hart Publishing.

Bobbio, Norberto (2004). A era dos direitos (tradução de Carlos Nelson Coutinho), Rio de Janeiro: Elsevier.

Boutcher, Steven A. (2010). 'Mobilizing in the Shadow of the Law: Lesbian and Gay Rights in the Aftermath of Bowers v. Hardwick.' Research in Social Movements, Conflict and Change 31: 175-205.

Burstein, Paul / Kathleen Monaghan (1986). 'Equal Employment Opportunity and the Mobilization of Law.' Law \& Society Review 20: 355-88.

Cohen, J. L. / Andrew Arato (1992). Civil Society and Political Theory. Cambridge, Mass: MIT Press.

Comaroff, John L. (2001). "Colonialism, culture, and the law: A foreword." Law \& 
Social Inquiry 26, no. 2 (2001): 305-314: 306

Comaroff, Jean / John Comaroff (2006). Law and Disorder in the Postcolony. University of Chicago Press.

Contiades, Xenophon / Alkmene Fotiadou (2013). Engineering Constitutional Change: A Comparative Perspective on Europe, Canada, and the USA, Routledge.

Cover, Robert M (1982). “The Supreme Court, 1982 Term - Foreword: Nomos and Narrative", Harvard Law Review 97(4).

Dahl, Robert (1957). "Decision-Making in a Demcoracy: The Supreme Court as Policy-Maker", Journal of Public Law, 6(2).

Dudziak, Mary L. "The Court and Social Context in Civil Rights History", The University of Chicago Law Review, 72(429).

Dworkin, Ronald (1977). Taking Rights Seriously. Cambridge (Mass.): Harvard University Press.

Dworkin, Ronald (1985). A Matter of Principle. Cambridge (Mass.): Harvard University Press.

Dworkin, Ronald (1986). Law's Empire. Cambridge (Mass.): Harvard University Press.

Epp, Charles R. (1998). The Rights Revolution: Lawyers, Activists, and Supreme Courts in Comparative Perspective. Chicago, IL:University of Chicago Press.

Epstein, Lee / Joseph F. Kobylka. (1992). The Supreme Court and Legal Change: Abortion and the Death Penalty. Chapel Hill, NC: University of North Carolina Press.

Eskridge, Jr., William N. (2000), "No Promo Homo: The Sedimentation of Anti-Gay Discourse and the Channeling Effect of Judicial Review". New York University Law Review, 1327(14905).

Eskridge, Jr., William N. (2002a). Equality Practice: Civil Unions and the Future of Gay Rights. New York: Routledge. 
Eskridge, Jr., William N. (2002b). "Some Effects of Identity-Based Social Movements on Constitutional Law in the Twentieth Century", Michigan Law Review, $100(8)$.

Eskridge, Jr., William N. (2005), "Pluralism and Distrust: How Courts Can Support Democracy by Lowering the Stakes of Politics", Yale Law Journal, 1279(1326).

Eskridge, Jr., William N. (2011), “Channeling: Identity-based social movements and public law", University of Pennsylvania Law Review, 150(419).

Eskridge, Jr. William N. (2013), "Backlash Politics: How Constitutional Litigation Has Advanced Marriage Equality in the United States". Boston University Law Review, 93(275).

Feeley, Malcolm (1992). "Hollow Hopes, Flypaper, and Metaphors", Law \& Soc. Inquiry 745(17).

Fisher, Louis (1987), "Social Influences on Constitutional Law”, J. Pol. Sci. 7(15).

Fisher, Louis (1988). Constitutional Dialogues: Interpretation As Political Process. Princeton University Press.

Galanter, Marc (19740. 'Why the 'Haves' Come Out Ahead: Speculations on the Limits of Legal Change.' Law and Society Review 9: 95-160

Gibson, James L. / Gregory A. Caldeira / Lester Kenyatta Spence (2003a). "The Supreme Court and the US Presidential Election of 2000: Wounds, Self-Inflicted or Otherwise?” British Journal of Political Science, 33(4), 535-556.

Gibson, James L. / Gregory A. Caldeira, / Lester Kenyatta Spence (2003b). "Measuring Attitudes toward the United States Supreme Court" American Journal of Political Science, 47(2).

Ginsburg, Tom (2010), "Written Constitutions and the Administrative State: On the Constitutional Character of Administrative Law" in Susan Rose-Ackerman \& Peter L. Lindseth (eds.), Comparative Administrative Law (Cheltenham: Edward Elgad).

Glendon, Mary Ann. Abortion and Divorce in Western Law, Cambridge, Mass: 
Harvard University Press.

Gloppen, Siri (2006), "Courts and Social Transformation: An Analytical Framework" in Roberto Gargarella / Pilar Domingo / Theunis Roux (eds.) Courts and Social Transformation in New Democracies - An Institutional Voice for the Poor?. Aldershot/Burlington: Ashgate.

Gloppen, Siri (2017). “Conceptualizing Lawfare”, artigo ainda não publicado, citação expressamente autorizada pela autora.

Gomes, Juliana Cesário Alvim (2016). Por um constitucionalismo difuso: Cidadãos, movimentos sociais e o significado da constituição. Salvador: JusPODIVM.

Häberle, Peter (2002). Hermenêutica constitucional - A sociedade aberta dos interpretes da Constituição: Contribuição para a interpretação pluralista $e$ procedimental da Constituição. (Tradução de Gilmar Ferreira Mendes) Porto Alegre: Editora Sérgio Antonio Fabris.

Habermas, Jürgen (1997). Direito e democracia: entre facticidade e validade. v. 1 e 2 Rio de Janeiro: Tempo Brasileiro.

Habermas, Jürgen (2001). "Constitutional Democracy: A Paradoxical Union of Contradictory Principles?", Political Theory, 766(29).

Habermas, Jürgen (2002). A inclusão do outro. São Paulo: Edições Loyola.

Hall, Kermit L. / James W. Ely (2009), United States Supreme Court Decisions, New York: Oxford University Press.

Handler, Joel (1978). Social Movements and the Legal System, New York: Academic Press.

Horowitz, Donald L. (1977). The Courts and Social Policy, Washington, DC: Brookings Institution.

Hirschl, Ran (2004a). “Juristocracy'- Political, not Juridical”. Pp 6-11 in The good Society, vol. 13, no. 3.

Hirschl, Ran (2004b). Towards Juristocracy: The Origins and Consequences of the 
New Constitutionalism. Cambridge, Mass: Harvard University Press.

Hoekstra, Valerie J. Public Reaction to Supreme Court Decisions. Cambridge University Press: 2003.

Jacobsohn, Gary J. (2010). Constitutional Identity, Cambridge, Mass: Harvard University Press.

Kavanagh, Aileen (2015). "What's so Weak about 'Weak-Form Review'? The Case of the UK Human Rights Act 1998”, University of Oxford Legal Research Paper Series.

King, Jeff (2012), Judging Social Rights, Cambridge University Press.

Klarman, Michael J. (1994), "How Brown Changes Race Relations: The Backlash Thesis". The Journal of American History, 81(1).

Klarman, Michael J. (2001), "How Great Were the "Great" Marshall Court Decisions?", Virginia Law Review, 87(6).

Klarman, Michael J. (2004), From Jim Crow to Civil Rights: The Supreme Court and the Struggle for Racial Equality, Oxford University Press.

Klarman, Michael J. (2005), "Brown and Lawrence (and Goodridge)". Michigan Law Review, 431(445).

Klarman, Michael J. (2011), "Courts, Social Change and Political Backlash", Hart Lecture at Georgetown Law Center, March 31, 2011, p. 1-11, Speaker's Notes, $<$ disponível em http://scholarship.law.georgetown.edu/cgi/viewcontent.cgi?article=1001\&context=har tlecture, último acesso em 24.6.2017>.

Krieger, Linda H. (2000), “Socio-Legal Backlash”. Berkeley Journal of Employment and Labor Law, 21(1).

Kritzer, Herbert M. (2001). "The Impact of Bush v. Gore on public perceptions and knowledge of the Supreme Court". Judicature, 85 (1).

Langford, Malcolm (org.) (2008). Social Rights Jurisprudence: Emerging Trends in 
International and Comparative Law. Cambridge University Press.

Lavalle, Adrián Gurza / Graziela Castello / Renata Mirándola Bichir (2004), “Quando novos atores saem de cena: continuidades e mudanças na centralidade dos movimentos sociais", Politica \& Sociedade, 5.

Levinson, Daryl J., Richard H. Pildes (2006). "Separation of Parties, not Powers". Harvard Law Review, 119(8).

Levinson, Sanford (2011). Constitutional Faith, (2d ed.), Princeton University Press.

Levinson, Sanford / Jack M. Balkin (2016). "Democracy and Disfunction: an Exchange”. Faculty Scholarship Series, 5170.

Levitsky, Sandra (2006). "To Lead with Law: Reassessing the Influence of Legal Advocacy Organizations in Social Movement" in Austin Sarat / Stuart A. Scheingold (eds.), Cause Lawyers and Social Movements, CA: Stanford University Press.

Madison, James / Alexander Hamilton / Jay John (1993). Os Artigos Federalistas. (tradução de Maria Luiza X. de A. Borges) Rio de Janeiro: Nova Fronteira.

McCammon, Holly / Allison R. McGrath (2015). "Litigating Change? Social movements and the court system, Sociology Compass 9/2: 128-139, 10.1111.

McCann, Michael W. (1994). Rights at Work: Pay Equity Reform and the Politics of Legal Mobilization. Chicago, IL: University of Chicago Press.

McCann, Michael. (2004). 'Law and Social Movements.' In Austin Sarat / Malden (eds.), The Blackwell Companion to Law and Society, MA: Blackwell Publishing.

McCarthy, John D. / Mayer N. Zald. (1977). 'Resource Mobilization and Social Movements: A Partial Theory.' American Journal of Sociology 82: 1212-41.

Melucci, Alberto (1985). "The Symbolic Challenge of Contemporary Movements", Social Research 52(4).

Melo, Rurion (2013). Marx e Habermas: teoria crítica e os sentidos da emancipação. São Paulo: Saraiva. 
Melo, Rurion (2014). "Da teoria à práxis: Honneth e as lutas por reconhecimento na teoria política contemporânea", Revista Brasileira de Ciência Política, 15, pp. 17-36.

Melo, Rurion (2015). "Repensando a esfera pública: esboço de uma teoria crítica da democracia”. Lua Nova: São Paulo, 94:11-39.

Mendes, Conrado H. (2011). Direitos fundamentais, separação de poderes $e$ deliberação. Série Direito, Desenvolvimento e Justiça, vol. 1. Ed. Saraiva: São Paulo.

Mendes, Conrado H. (2013). Constitutional Courts and Deliberative Democracy. Oxford University Press.

Meyer, David S. / Suzanne Staggenborg. (1996). 'Movements, Countermovements, and the Structure of Political Opportunity.', American Journal of Sociology 101: $1628-60$.

Mudrovitsch, Rodrigo de Bittencourt (2014). Destrincheiramento da jurisdição constitucional. São Paulo: Saraiva.

Murphy, Walter F. "Who Shall Interpret? The Quest for the Ultimate Constitutional Interpreter", Rev. Pol. 401(48).

Nino, Carlos Santiago (1996), The Constitution of Deliberative Democracy, Yale University Press.

O'Connor, Karen (1980). Women's Organizations' Use of the Courts. Lexington, MA: Lexington Books.

O’Connor, Karen / Lee Epstein. (1983). 'Beyond Legislative Lobbying: Women's Rights Groups and the Supreme Court.', Judicature 67: 134-43.

Piscitelli, Adriana (2009). "Gênero: a história de um conceito" in Heloísa Buarque de Almeida e José Szwako (org.), Diferenças, Igualdade, São Paulo: Berlendis \& Vertecchia.

Post, Robert C. (2003), "Foreword: Fashioning the Legal Constitution: Culture, Courts and Law". Harvard Law Review, 117(5). 
Post, Robert C. / Reva B. Siegel, (2007) "Roe Rage: Democratic Constitutionalism and Backlash”, Faculty Scholarship Series, 169.

Post, Robert C. / Reva B. Siegel (2009). "Democratic Constitutionalism" in Jack M. Balkin, Reva B. Siegel (org.), The Constitution in 2020. Nova York: Oxford University Press.

Rawls, John (2005), A Theory of Justice, Cambridge, Massachusetts/London: The Belknap press of Harvard University.

Rodríguez-Gavarito, César / Diana Rodríguez Franco (2010). Cortes y cambio social: como la Corte Constitucional transformó el desplazamiento forzado en Colombia. Bogotá: Colección Dejustícia.

Rodríguez-Garavito, César (2012). "Beyond the Courtroom: The Impact of Judicial Acitvism on Siocioeconomic Rights in Latin America”, Texas Law Review 1669(89).

Rosenberg, Gerald N. (1991). The Hollow Hope: Can Courts Bring About Social Change? Chicago: University of Chicago Press.

Rosenberg, Gerald N. (1992), "Judicial Independence and the Reality of Political Power", Review of Politics 369(54).

Rosenberg, Gerald N. (2006), "Courting Disaster: Looking for Change in All the Wrong Places", Drake Law Review, 795(813).

Rubenfeld, Jed (2001), Freedom and Time: A Theory of Constitutional SelfGovernment, New Haven: Yale University Press.

Rubin, Edward L. (2001). 'Passing through the Door: Social Movement Literature and Legal Scholarship.' University of Pennsylvania Law Review 150: 1-83.

Santos, Boaventura de S. (2002), Toward a New Legal Common Sense: Law, Globalization and Emancipation, London: Butterworths LexisNexis.

Sarat, Austin / Stuart Scheingold. (1998). Cause Lawyering: Political Commitments and Professional Responsibility. New York: Oxford University Press.

Sarat, Austin / Stuart Scheingold. (2006), Cause Lawyers and Social Movements. 
Stanford, CA: Stanford Law and Politics.

Sarmento, Daniel (2018). Direitos, Democracia e República: Escritos de Direito Constitucional, Belo Horizonte: Fórum.

Scheingold, Stuart A. 1974 [2004]. The Politics of Rights: Lawyers, Public Policy, and Political Change. Ann Arbor,MI:University of Michigan Press.

Segal, Jeffrey A. / Harold J. Spaeth. (2002). The Supreme Court and the Attitudinal Model Revisited. New York: Cambridge University Press.

Siegel, Reva B. (2006a). Constitutional Culture, Social Movement Conflict and Constitutional Change: The Case of the de facto ERA". Brennan Center Symposium Lecture. California Law Review, 94(5), pp. 1323-1419.

Siegel, Reva B. (2006b). "You've Come a Long Way, Baby: Rehnquist's New Approach To Pregnancy Discrimination in Hibbs", Stanford Law Review 58(6).

Sousa Júnior, José Geraldo de (2000), “Movimentos Sociais e Práticas Instituintes de Direito: Perspectivas para a Pesquisa Sócio-jurídica no Brasil”, Studia Jurídica, Boletim da Faculdade de Direito da Universidade de Coimbra

Stern, Felice A. (1965), “Backlash”, American Speech, 40(2).

Sunstein, Cass R. (1996), "On The Expressive Function of Law”, E Eur Const Rev $66(5)$

Sunstein, Cass R. (2001). One Case at a Time: Judicial Minimalism on the Supreme Court. Harvard University Press.

Sunstein, Cass R. / David Schkade / Lisa Michelle Ellman. (2004). "Ideological Voting on Federal Courts of Appeals: A Preliminary Investigation", Virginia Law Review 90: 301-54.

Tarrow, Sidney. O poder em movimento: Movimentos sociais e confronto Político. Petrópolis: Vozes, 2009.

Tocqueville, Alexis De (1977 [1835], Democracia na América, tradução de Neil Ribeiro da Silva, 2a ed., Belo Horizonte: Ed. Itatiaia. 
Tsutsui, Kiyoteru / Claire Whitlinger / Alwyn Lim (2012), “International Human Rights Law and Social Movements: States' Resistance and Civil Society's Insistence", Annual Review of Law and Social Science, 8.

Tushnet, Mark V. (1987). The NAACP's Legal Strategy against Segregated Education - 1925-1950. Chapel Hill, NC: University of North Carolina Press.

Tushnet, Mark (1995). "Policy Distortion and Democratic Debilitation: Comparative Illumination of the Counter-Majoritarian Difficulty", Michigan Law Review, 94.

Tushnet, Mark (1996), "Living in a Constitutional Moment?: Lopez and Constitutional Theory", Case W. Res. L. Rev., 846(46).

Tushnet, Mark (1999). Taking the Constitution Away from the Courts. Princeton: Princeton University Press.

Tushnet, Mark (2006), "Popular Constitutionalism as Political Law", Chicago-Kent Law Review, 81.

Tushnet, Mark (2008). Weak Courts, Strong Rights: Judicial Review and Social Welfare Rights in Comparative Constitutional Law. Princeton: Princeton University Press.

Tushnet, Mark (2011). "Skepticism about Judicial Review - A Perspective From the United States", in Tom Campbell / Keith Ewing / Adam Tomkins (eds). Skeptical Approaches to entrenched human rights. Oxford University Press.

Unger, Roberto Mangabeira (2001). Politica: Os Textos Centrais. 1a Ed., Rio de Janeiro: Boitempo.

Valle, Vanice Regina Lírio do (2013), “Backlash à decisão do Supremo Tribunal Federal: pela naturalização do dissenso como possibilidade democrática" < disponível em

$<$ www.academia.edu/5159210/Backlash \%C3\%A0_decis\%C3\%A3o_do_Supremo_T ribunal_Federal_pela_naturaliza $\% \mathrm{C} 3 \% \mathrm{~A} 7 \% \mathrm{C} 3 \% \mathrm{~A} 30$ do_dissenso_como_possibilida de_democr\%C3\%A1tica, último acesso em 26.6.2017>. 
Vermeule, Adrian (2006). Judging Under Uncertainty: An Institutional Theory of Legal Interpretation. Harvard University Press.

\section{Material encontrado em sites}

Datafolha, "Os números da violência contra mulheres no Brasil" < disponível em http://exame.abril.com.br/brasil/os-numeros-da-violencia-contra-mulheres-no-brasil/ último acesso em 10.8.2018>.

Estudo Consultoria Santo Caos, “A discriminação da população LGBT no mercado de trabalho" $<$ disponível em https://gabrielapassatore.jusbrasil.com.br/noticias/338644133/a-discriminacao-dapopulacao-lgbt-no-mercado-de-trabalho último acesso em 10.8.2018>.

Grupo Gay da Bahia, "Número de mortes de LGBT's bate recorde em 2016" $<$ disponível em http://blogs.correio24horas.com.br/mesalte/numero-de-mortes-delgbts-bate-recorde-em-2016-bahia-teve-32-homicidios/ último acesso em 10.8.2018>.

IBGE, "Estatísticas de gênero do IBGE mostra dados relevantes sobre a autonomia econômica das mulheres" <disponível em http://www.sof.org.br/2015/06/12/publicacao-estatisticas-de-genero-do-ibge-mostradados-relevantes-sobre-a-autonomia-economica-das-mulheres/ último acesso em $10.8 .2018>$.

IPEA, "70\% das vítimas são crianças e adolescentes: os dados sobre estupro no Brasil" <disponível em http://www.bbc.com/portuguese/brasil-36401054 último acesso em 10.8.2018>.

OMS, "ONU: Taxa de feminicídio no Brasil é a quinta maior do mundo; diretrizes nacionais buscam solução" https://nacoesunidas.org/onu-feminicidio-brasil-quintomaior-mundo-diretrizes-nacionais-buscam-solucao/

Secretaria de Direitos Humanos da Presidência da República, "Relatório sobre Violência Homofóbica no Brasil de 2013” <disponível em http://www.brasil.gov.br/cidadania-e-justica/2013/06/brasil-divulga-dados-sobre-aviolencia-contra-gays-lesbicas-e-travestis último acesso em 10.8.2018>. 
Transgender Europe, "ONU: Taxa de feminicídios do Brasil é a quinta maior do mundo; diretrizes nacionais buscam solução" <disponível em http://agenciabrasil.ebc.com.br/direitos-humanos/noticia/2015-11/com-600-mortesem-seis-anos-brasil-e-o-que-mais-mata-travestis-e último acesso em 10.8.2018>. 